\title{
Контактные сопротивления в составных термоэлектрических ветвях
}

\author{
() И.А. Драбкин, В.Б. Освенский, А.И. Сорокин, В.П. Панченко, О.Е. Нарожная \\ АО „Гиредмет“, \\ 119017 Москва, Россия \\ E-mail: igordrabk@gmail.com
}

(Получена 31 января 2017 г. Принята к печати 8 февраля 2017 г.)

Разработан метод измерения контактных сопротивлений секционированных термоэлектрических ветвей. Чувствительность метода $2 \cdot 10^{-6} \mathrm{OM} \cdot \mathrm{cm}^{2}$. Измерены контактные сопротивления при коммутации секций различных термоэлектрических материалов. И коммутация, и материалы секций получены различными методами. Полученные значения контактных сопротивлений лежат в пределах $0.8-3.5$ Ом см $^{2}$. Оценки показывают, что при таких контактных сопротивлениях для 4 секций при высоте ветви $\sim 1$ см потери кпд в худшем случае составят не более $5 \%$.

DOI: $10.21883 /$ FTP.2017.08.44782.51

Контактные сопротивления являются одной из причин того, что в термоэлектрических преобразователях (как холодильных, так и генераторных) не реализуются в полной мере свойства термоэлектрического материала. Это связано с тем, что к электрическому сопротивлению ветви прибавляется контактное сопротивление, уменьшая действующее значение термоэлектрической эффективности. Особенно это должно быть заметно для составных многосекционных ветвей, в которых контактные сопротивления возникают не только на концах ветви, но и на границах секций. Поэтому измерение контактных сопротивлений представляет несомненный интерес для разработчиков термоэлектрических приборов. Нами была разработана установка для измерения контактных сопротивлений методом скачка потенциала на контактном сопротивлении при пропускании через ветвь электрического тока. Контактные сопротивления существенно зависят как от технологии получения термоэлектрических материалов, так и от технологии формирования контактов, так как контактное сопротивление обусловлено отсутствием идеальной контактной структуры (наличием нарушенного слоя, отсутствием сплошности контактной поверхности, ее неплоскостностью и т.п.) [1-5].

В данной работе изучались контактные сопротивления на секционированных ветвях термоэлектрических генераторов, в которых отдельные секции, полученные различными методами, соединены между собой пайкой или методом искрового плазменного спекания (SPS). Принцип измерений схож с приведенным в работе [6].

Пусть имеется образец, состоящий из полупроводникового материала с металлическим контактом. Скачок потенциала $\Delta U$ на контактном сопротивлении связан с пропускаемым через образец током соотношением

$$
\Delta U=\frac{I R_{c}}{s}
$$

где $I-$ ток через образец, $R_{c}$ - удельное контактное сопротивление, $s$ - площадь поперечного сечения образца. Из соотношения (1) видно, что для увеличения чувствительности необходимо увеличивать ток через исследуемый образец и уменьшать его поперечное сечение.

Площадь поперечного сечения образца в наших экспериментах составляла 4 мм² $^{2}$. Через образец пропускали переменный ток частотой 1 кГц и величиной до $1 \mathrm{~A}$. Пайку токовых проводов к образцу осуществляли через токовыравнивающие медные пластины, припаянные к торцам образца. Образец для уменьшения влияния нагрева на результаты измерений размещался на изолирующей подложке из керамики с высокой теплопроводностью. Для улучшения теплового контакта с подложкой использовали теплопроводную пасту КПТ-8. Сканирование потенциала по длине образца осуществляли перемещением вольфрамового зонда вдоль образца микрометрическим винтом с ценой деления 10 мкм. Для измерения потенциала использовали мультиметр Keithley-2000. Чувствительность установки при измерении образцов с удельным сопротивлением $10^{-3} \mathrm{OM} \cdot \mathrm{cm}$ составляла $2 \cdot 10^{-6} \mathrm{OM} \cdot \mathrm{cm}$.

Изображение ряда отпечатков, оставленных зондом на измеряемом образце, приведено на рис. 1.

На рис. 2 приведены результаты измерений распределения потенциала вдоль SPS-спеченных образцов, состоящих из $\mathrm{Bi}_{2} \mathrm{Te}_{2.7} \mathrm{Se}_{0.3}+\mathrm{Mo}+\mathrm{Ni}+$ припой $+\mathrm{Ni}+\mathrm{Mo}+n$-PbTe. $\mathrm{Bi}_{2} \mathrm{Te}_{2.7} \mathrm{Se}_{0.3}$ и РbТе получали методом SPS. Слои Мо и Ni наносили плазменным напы-

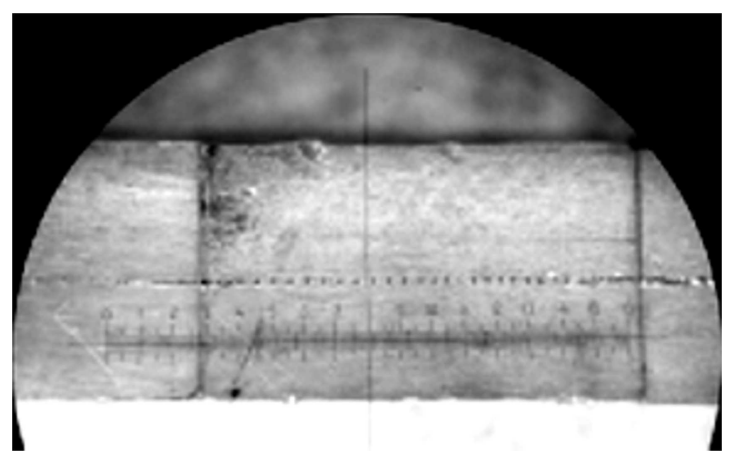

Рис. 1. Фотография отпечатков зонда на образце. Цена одного большого деления на шкале 200 мкм. 
Результаты измерений контактного сопротивления различных пар термоэлектрических материалов

\begin{tabular}{|c|c|c|c|c|c|}
\hline $\begin{array}{c}\text { Номер } \\
\text { образца }\end{array}$ & $\begin{array}{c}\text { Материалы } \\
\text { секций ветви }\end{array}$ & $\begin{array}{c}\text { Способ } \\
\text { получения секций }\end{array}$ & $\begin{array}{c}\text { Материалы } \\
\text { металлических } \\
\text { покрытий секций }\end{array}$ & $\begin{array}{c}\text { Способ } \\
\text { соединения секций }\end{array}$ & $\begin{array}{c}\text { Граница между секциями } \\
(\mathrm{N})-(\mathrm{N}+1) / \text { контактное } \\
\text { сопротивление } \\
R_{c} \cdot 10^{5}, \text { Ом } \cdot \mathrm{cm}^{2}\end{array}$ \\
\hline 1 & $\begin{array}{l}\text { (1) } \mathrm{Bi}_{2} \mathrm{Te}_{2.85} \mathrm{Se}_{0.15}- \\
-(2) \mathrm{PbTe}_{0.995} \mathrm{I}_{0.005}\end{array}$ & $\begin{array}{l}(1) \text { - экструзия, } \\
(2) \text { - горячее } \\
\text { прессование }\end{array}$ & $\begin{array}{l}\text { Мo, Ni - плазменное } \\
\text { напыление }\end{array}$ & Пайка & $(1)-(2) / 1.6$ \\
\hline 2 & $\begin{array}{l}\text { (1) } \mathrm{Bi}_{2} \mathrm{Te}_{2.85} \mathrm{Se}_{0.15}- \\
-(2) \mathrm{PbTe}_{0.995} \mathrm{I}_{0.005}\end{array}$ & $\begin{array}{l}(1) \text { - экструзия, } \\
(2) \text { - горячее } \\
\text { прессование }\end{array}$ & $\begin{array}{l}\text { Мо, } \mathrm{Ni} \text { - плазменное } \\
\text { напыление }\end{array}$ & Пайка & $(1)-(2) / 1.3$ \\
\hline 3 & $\begin{array}{l}\text { (1) } \mathrm{Bi}_{0.4} \mathrm{Sb}_{1.6} \mathrm{Te}_{3}- \\
-(2) \mathrm{Bi}_{0.27} \mathrm{Sb}_{1.73} \mathrm{Te}_{3}- \\
-(3) \mathrm{GeTe}\end{array}$ & \begin{tabular}{|l}
$(1)$ - экструзия, \\
$(2)$ - экструзия \\
$(3)$ - SPS-прессование
\end{tabular} & $\begin{array}{l}\text { Мo, } \mathrm{Ni} \text { - плазменное } \\
\text { напыление }\end{array}$ & Пайка & $(2)-(3) / 1.0$ \\
\hline 4 & $\begin{array}{l}(1) \mathrm{Bi}_{2} \mathrm{Te}_{2.7} \mathrm{Se}_{0.3}- \\
-(2) \mathrm{Bi}_{2} \mathrm{Te}_{2.85} \mathrm{Se}_{0.15}- \\
-(3) \mathrm{PbTe}_{0.995} \mathrm{I}_{0.005}\end{array}$ & \begin{tabular}{|l}
$(1)$ - экструзия, \\
$(2)$ - экструзия, \\
$(3)$ - SPS-прессование
\end{tabular} & $\begin{array}{l}\text { Мo, } \mathrm{Ni} \text { - плазменное } \\
\text { напыление }\end{array}$ & Пайка & $(2)-(3) / 1.1$ \\
\hline 5 & $\begin{array}{l}\text { (1) } \mathrm{Bi}_{2} \mathrm{Te}_{2.7} \mathrm{Se}_{0.3}- \\
-(2) \mathrm{Bi}_{2} \mathrm{Te}_{2.85} \mathrm{Se}_{0.15}- \\
-(3) \mathrm{PbTe}_{0.995} \mathrm{I}_{0.005}\end{array}$ & \begin{tabular}{|l}
$(1)$ - экструзия, \\
$(2)$ - экструзия, \\
$(3)$ - SPS-прессование
\end{tabular} & $\begin{array}{l}(1)-(2): \text { металлизация } \\
\text { отсутствует; } \\
(2)-(3): \mathrm{Mo}, \mathrm{Ni}- \\
\text { плазменное } \\
\text { напыление }\end{array}$ & $\begin{array}{l}(1)-(2): \text { SPS-спекание; } \\
(2)-(3): \text { пайка }\end{array}$ & $\begin{array}{l}(1)-(2) / 2.0 \\
(2)-(3) / 3.0\end{array}$ \\
\hline 6 & $\begin{array}{l}(1) \mathrm{Bi}_{2} \mathrm{Te}_{2.7} \mathrm{Se}_{0.3}- \\
-(2) \mathrm{Bi}_{2} \mathrm{Te}_{2.85} \mathrm{Se}_{0.15}- \\
-(3) \mathrm{PbTe}_{0.995} \mathrm{I}_{0.005}\end{array}$ & \begin{tabular}{|l}
$(1)$ - экструзия, \\
$(2)$ - экструзия, \\
$(3)$ - SPS-прессование
\end{tabular} & $\begin{array}{l}(1)-(2): \text { металлизация } \\
\text { отсутствует; } \\
(2)-(3): \text { Mo, Ni - } \\
\text { плазменное } \\
\text { напыление }\end{array}$ & $\begin{array}{l}(1)-(2): \text { SPS-спекание; } \\
(2)-(3): \text { пайка }\end{array}$ & $\begin{array}{l}(1)-(2) / 0.8 \\
(2)-(3) / 3.5\end{array}$ \\
\hline
\end{tabular}

лением. Толщина слоев составляла 70 мкм. На рис. 2 ясно видно, что при переходе от $\mathrm{Bi}_{2} \mathrm{Te}_{2.7} \mathrm{Se}_{0.3}$ к Мо наблюдается скачок потенциала. Расчет контактного сопротивления между $\mathrm{Bi}_{2} \mathrm{Te}_{2.7} \mathrm{Se}_{0.3}$ и Мо по формуле (1) дает значение $1.6 \cdot 10^{-5} \mathrm{OM} \cdot \mathrm{cm}^{2}$. Между Мо и $n$-РbТе заметного скачка сопротивления не наблюдается. Для оценки верхней границы контактного сопротивления в

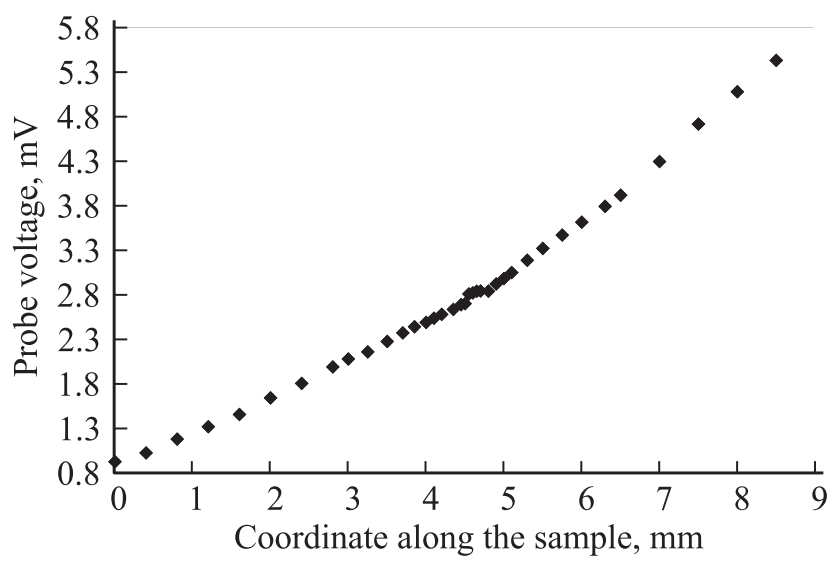

Pис. 2. Изменение потенциала вдоль образца $\mathrm{Bi}_{2} \mathrm{Te}_{2.7} \mathrm{Se}_{0.3}+$ $+\mathrm{Mo}+\mathrm{Ni}+$ припой $+\mathrm{Ni}+\mathrm{Mo}+n$-PbTe. Скачок потенциала вблизи границы секций наблюдается около значения на оси координаты $4.5 \mathrm{Mм}$. этом случае для скачка потенциала берем разность потенциалов между соседними точками на границе. Такая оценка дает, что контактное сопротивление на границе Мо и $n$-PbTe $<10^{-5}$ Ом $\cdot$ см$^{2}$. Зависимость потенциала от координаты вдали от контактов позволяет определять удельное сопротивление образца.

Аналогичным образом определяли контактное сопротивление для других пар материалов. Результаты измерений приведены в таблице. Все секции ветви пронумерованы цифрами в круглых скобках. При использовании металлических покрытий указано, между какими секциями эти покрытия использовали. Контактные сопротивления также отнесены к границам соответствующих секций.

Из таблицы видно, что максимальное измеренное контактное сопротивление составляло $3.5 \cdot 10^{-5} \mathrm{OM} \cdot \mathrm{cm}^{2}$. Для того чтобы контактным сопротивлением можно было пренебречь, суммарное сопротивление всех секций ветви должно быть много больше суммы всех контактных сопротивлений, включая контактные сопротивления на концах ветви:

$$
\sum_{i} \rho_{m i} \frac{l_{i}}{s} \gg \sum_{j} \frac{R_{c j}}{s},
$$

где $\rho_{m i}-$ удельное сопротивление материала $i$-ой секции, $l_{i}$ - длина $i$-ой секции, суммирование ведется 
по всем секциям, $R_{c j}-$ контактное сопротивление на границах секций, суммирование по $j$ ведется по всем секциям и включает контактные сопротивления на концах ветви. Пусть удельное сопротивление каждой секции составляет $10^{-3} \mathrm{OM} \cdot \mathrm{cm}$, число секций 4 , контактное сопротивление $3.5 \cdot 10^{-5} \mathrm{OM} \cdot \mathrm{cm}^{2}$, тогда оценка для суммарной длины ветви:

$$
l \gg \frac{3 \cdot 10^{-5} \cdot 6}{10^{-3}}=0.18 \mathrm{~cm}
$$

Эта оценка показывает, что даже в случае самых больших из полученных нами контактных сопротивлений для ветви длиной 1.8 см влияние контактного сопротивления на термоэлектрическую эффективность $Z$ не будет превышать 10\%. Дифференцируя стандартное выражение для кпд термоэлемента ( $\eta)$ [7], можно получить

$$
\frac{d \eta}{\eta}=\frac{1+T_{c} / T_{h}}{2 M\left(M+T_{c} / T_{h}\right)} \frac{d Z}{Z}<\frac{1}{2} \frac{d Z}{Z}
$$

где $T_{h}, T_{c}$ - температуры соответственно горячего и холодного концов термоэлемента, $M=\sqrt{1+(1 / 2) Z\left(T_{h}+T_{c}\right)}$. Таким образом, в худшем случае $\eta$ уменьшится на $5 \%$.

Работа выполнена при финансовой поддержке Министерства образования и науки РФ (субсидия № RFMEF157914X0039-14.579.21.0039).

\section{Список литературы}

[1] М.В. Астахов, В.Т. Бублик, В.В. Каратаев, Н.В. Малькова, В.Б. Освенский, Т.Б. Сагалова, Н.Ю. Табачкова. В сб.: Термоэлектрики и их применение (СПб., 2004) с. 243.

[2] В.Б. Освенский, В.В. Каратаев, Н.В. Малькова, В.Т. Бублик, Ю.В. Гостев, Т.Б. Сагалова, Н.Ю. Табачкова. В сб.: Термоэлектрики и их применение (СПб., 2000) с. 48.

[3] R. Holm. Electric Contacts Handbook (Springer-Verlag, Berlin, Heidelberg, 1958).

[4] M. Braunovich, V.V. Konchits, N.K. Myshkin. Electrical Contacts. Fundamentals, Applications and Technology (CRC Press, 2006).

[5] И.А. Драбкин, Л.Б. Ершова. В сб.: Термоэлектрики и их применение (СПб., 2008) с. 408.

[6] С.М. Городецкий, И.А. Драбкин, И.В. Нельсон. Завод. лаб., № 12, 49 (1984).

[7] А.С. Охотин, А.А. Ефремов, В.С. Охотин, А.С. Пушкарский. Термоэлектрические генераторы (М., Атомиздат, 1976).

Редактор Л.В. Шаронова

\section{Contact resestance in spark plasma sintered segmented legs}

\author{
I.A. Drabkin, V.B. Osvensky, A.I. Sorokin, \\ V.P. Panchenko, O.E. Narozhnaia \\ JSC „GIREDMET“, \\ 119017 Moscow, Russia
}

Abstract A method for measuring the contact resistance of the thermoelectric segmented legs has been devised. The sensitivity of the method is $2 \cdot 10^{-6} \Omega \cdot \mathrm{cm}^{2}$. The contact resistance of the junctions between the different segments of the thermoelectric materials was measured. Both the junctions and the materials of different sections were obtained by various ways. The resulting contact resistance values are in the range $0.8-3.5 \Omega \cdot \mathrm{cm}^{2}$. The estimates show that the contact resistance for such 4-segment leg of the height order of $1 \mathrm{~cm}$ reduces the efficiency at most by $5 \%$. 